\title{
Risky Business: Applying Ethical Standards to Social Media Use with Vulnerable Populations
}

\author{
Hillary Rose Dolinsky \\ Natalie Helbig
}

\begin{abstract}
Social media is changing how those in the helping professions offer clinical, medical, or educational services, provide referrals, administer therapeutic interventions, and conduct research. Non-profits and government organizations working with vulnerable populations need to consider the possibility of ethical missteps when using social media. A comparison of Facebook strategies used with the National Youth in Transition Database (NYTD) program to engage and locate current and former youth in the foster care system was conducted. Facebook practices and strategies were examined based on the current National Association of Social Workers (NASW) Code of Ethics and the Association of Social Work Boards (ASWB) Standards for Technology and Social Work Practice. The ethical standards examined included obtaining consent, preserving confidentiality, verifying youth identity online, and avoiding disclosure of foster care affiliation. Findings provide valuable insight for further discussions around ethical standards in light of the rapidly changing uses of technology in social work. In addition, we illustrate guidelines and best practices used when adopting social media tools for interacting with vulnerable populations.
\end{abstract}

Keywords: Social media policy, ethics, social work administration, vulnerable populations

Social media and social networking sites (SNS) are playing a greater role in various aspects of child welfare practices. Examples range from providing counseling, therapy, and self-guided interventions to finding prospective adoptive parents (Reamer, 2013) or tracing research participants in long-term outcomes-based research (Balfe, Hackett, Masson, \& Phillips, 2013). The accessibility of social media and SNS enables non-profit and government agencies to easily use the power of these tools for information dissemination, resource referral, intervention provision, or tracking. However, one major reason government agencies, regardless of policy area, are hesitant to use social media and SNS in the delivery of public services is the perceived and real risks of security, privacy, records management, and legal issues associated with terms of service (National Association of State Chief Information Officers [NASCIO], 2010; Oxley, 2011). These issues become even more risky for agencies working with vulnerable populations.

State agencies and non-profit organizations likely have some type of acceptable use policy for social media within the organization; however, many are not likely to have guidelines or policies that target use in professional practice. Likewise, the current National Association of Social Workers (NASW) Code of Ethics has limited guidance directly related to the use of these new technologies for practice and administration of programs (NASW, 2005, 2008).

Hillary R. Dolinsky, LMSW is a Program Associate at the Center for Technology in Government at the University at Albany, State University of New York. Albany, NY. Email: hdolinsky@ctg.albany.edu. Natalie Helbig, PhD is a Senior Research Associate at the Center for Technology in Government at the University at Albany. Albany, NY. Email: nhelbig@albany.edu.

Copyright (C) 2015 Advances in Social Work Vol. 16 No. 1 (Spring 2016), 55-66 


\section{Literature Review}

An emerging body of research is starting to call attention to the type of SNS used and the implications of their use with respect to ethical standards, particularly for those who identify as a member of a vulnerable population (American Youth Policy Forum, 2014; Reamer, 2013; Sewpaul \& Jones, 2004). For example, if a victim of domestic violence participates in an online social media group for survivors, that interaction is at risk of being made public knowledge. The interaction may not only allow for her social media network to know that she is a victim, but her perpetrator may also be able to locate her as a result, possibly placing her at risk for further abuse. Many kinds of unintentional mistakes can often be mitigated by designing informative guidelines or social media policies (Hrdinova, Helbig \& Stollar-Peters, 2010; Reamer, 2013). Non-profits and government organizations that cater to a specific vulnerable population need to develop detailed social media policies that outline how the organization is going to engage with their consumers while still protecting identities and avoiding undue risk or harm as a result of participation in an online relationship.

\section{The NASW Code of Ethics}

The NASW Code of Ethics dates back to 1960 and includes 14 statements on best practices in social work (Congress \& McAuliffe, 2006). Last revised in 2008, the NASW Code of Ethics has evolved to feature ethical principles valued by the profession and ethical standards of practice, each outlining behavioral expectations, reporting requirements, professional obligations, and responsibilities that social workers have to broader society (NASW, 2008). To update the NASW Code of Ethics, approval is required from its Delegate Assembly. Consisting of elected NASW members, the Delegate Assembly meets every three years to approve policies and revisions proposed by the association (Congress \& McAuliffe, 2006).

Although the NASW Code of Ethics describe what social workers should value and what rules they should abide by, it has been critiqued for its inability to translate the principles and standards into practice, particularly with regards to utilizing technology within social work (Perron, Taylor, Glass, \& Margerum-Leys, 2010). There is limited guidance on how to apply the ethical standards within the context of social work practice.

In an effort to evaluate the NASW Code of Ethics, researchers at the University of Michigan, Washington University, and Eastern Michigan University compared specific standards from the code to the importance of teaching information and computer technologies (ICTs) in social work education. For example, NASW ethical standard 3.07 states that "social work administrators should advocate within and outside their agencies for adequate resources to meet clients' needs" (NASW, 2008, p. 20). Based on their own interpretation, the research team used this standard to encompass the importance for social workers to obtain real-time data, adopt open source software, and consider cloud computing as a reasonable alternative to issues of remote data storage and security (Perron et al., 2010).

These researchers were able to loosely interpret the NASW Code of Ethics and compare them to their ICT research and social work education agenda. As intended, the 
NASW Code of Ethics leaves enough room for open interpretation to accommodate a wide variety of practice settings and situational dilemmas. However, open interpretation may also leave room for disparity in how non-profits, government agencies, and social work clinicians perceive the NASW Code of Ethics.

\section{The ASWB Standards for Technology and Social Work Practice}

With the emergence of ICTs, the NASW teamed up with the Association of Social Work Boards (ASWB) in 2005 to create the ASWB Standards for Technology and Social Work Practice. Similar to the NASW Code of Ethics, the ASWB Standards for Technology dictate specific principles and expected practitioner efforts in verifying client identity, preserving confidentiality, and obtaining consent when using technology. Even though the ASWB believes that "social workers should acquire skills that use technology appropriately and adapt traditional practice protocols to ensure competent and ethical practice," (NASW, 2005, p. 4) no guidance is offered on how to apply the technology standards within a clinical, non-profit, or government environment, leaving implementation and enforcement of the ethical standards to the interpretation of decision makers.

\section{Case Study - The National Youth in Transition Database (NYTD)}

The National Youth in Transition Database (NYTD) is a federal data collection effort on youth in the child welfare system who are transitioning to independent living. Every three years, a new cohort of youth turning 17 while in foster care participates in the NYTD survey, reporting independent living services received to the state and federal government. If youth participate in an NYTD survey at age 17, they are eligible to participate again at age 19 and 21, illustrating which services are used while youth are in foster care and what services are used or needed once they leave the foster care system. Youth aging out of the foster care system are not only a vulnerable population but also can be difficult to maintain communication with. Their nomadic tendencies and changing addresses and phone numbers require non-profits and agencies seeking to engage with this population over time to consider additional outreach methods.

States are responsible for creating systems for surveying and tracking youth until they are 21. Once a young person leaves care, their information is not updated and the state has a limited relationship with them. In order to create an engagement strategy and tracking mechanism, several states turned to the use of social media. One interviewee, "I came into this knowing that the easiest way to be able to reach the youth at 19 and 21 years old was to reach out to them on their level," adding that Facebook was a preferred social media tool to help make finding these youth easier. Another state started using social media because "a lot of [foster youth] didn't have a phone number, but they had email addresses and they were always on Facebook, so it was easier for [the youth]." Using Facebook with the NYTD not only allows NYTD administrators to use a method commonly used among youth in this age range but also offers an additional avenue for providing the survey and tracking youth throughout the data collection phase. 


\section{Methods}

\section{Sample}

We used our knowledge of the NYTD program and verified state NYTD Facebook activities through an online search in order to construct a convenience sample of states using Facebook for our study. After an initial scan, seven states were identified as using social media. We contacted each state representative for the NYTD program to construct a convenience sample of ten child welfare government employees, non-profit agency contractors, and university researchers to be interviewed, with at least one from each of the seven states. Initial contact was established through email invitations, and representatives were provided informed consent and further details about the goals of the study.

\section{Data Collection}

Semi-structured phone interviews were conducted with questions regarding social media goals, strategies, applications, practices, and outcomes. Each state representative was asked the same questions, although conversations frequently expanded beyond the interview questions to provide additional insight into each state's rationale for Facebook use within the NYTD. All interviews were conducted in June and July of 2013, and each lasted approximately 45 minutes.

\section{Data Analysis}

A review of the existing NASW Code of Ethics (NASW, 2008) and the ASWB Standards for Technology (NASW, 2005) was used to develop our analytic framework. We identified the following important ethical dimensions: (a) informed consent, obtaining consent from former or current foster youth to engage through Facebook; (b) confidentiality, ensuring that information shared through Facebook was kept private and confidential; (c) disclosure, avoiding the disclosure of foster care or child welfare involvement as a result of engaging through Facebook and (d) verification of identify, confirming and verifying the identity of former or current foster youth prior to initiating a Facebook relationship. All interviews were transcribed, and a coding instrument was developed. The team used various qualitative techniques for examining the transcripts. Summary practices were described, and various characteristics of Facebook strategies were outlined.

\section{Results}

Each of the seven cases varied in their approaches, resources, and overall processes for data collection, program structure, and social media use. Table 1 identifies the three models of Facebook use that were observed in the study. One model was an Open Page, which provides the public with unrestricted access to the NYTD content created by the state. This model is essentially a supplement to a website, and content is not private or hidden from users. The second model is a Private Group, which hides the membership of the Facebook group from other users and is considered closed to the public. In this 
model, only NYTD administrators of the Facebook group can send invitations to join the group. The third model is the use of a Professional Profile. The profile represents an actual person, not an organization. It is very similar to a personal profile, but the person is using their professional persona. A professional Facebook profile allows the person to send personal messages and have friends in contrast to an open Facebook page which cannot have friends, just followers.

\begin{tabular}{|c|c|c|}
\hline \multicolumn{3}{|c|}{ Table 1: Models of Facebook Strategies by States } \\
\hline Model & Description & \# of States* \\
\hline Open Page & $\begin{array}{l}\text { - Public has unrestricted access to content - no } \\
\text { hidden content } \\
\text { - Supplement to a website } \\
\text { - } \quad \text { No attached individual identity } \\
\text { - } \text { individual profiles } \\
\text { - } \quad \text { Limited means of interaction }\end{array}$ & 5 \\
\hline Private Group & $\begin{array}{l}\text { - } \quad \text { Membership is invitation only } \\
\text { - } \quad \text { Group does not show up in search results } \\
\text { - } \quad \text { Members carry same shared identity }\end{array}$ & 1 \\
\hline Professional Profile & $\begin{array}{l}\text { - } \quad \text { Represents an individual } \\
\text { - } \quad \text { Interactive capabilities include sending messages } \\
\text { and event invitations as well as posting photos } \\
\text { - } \quad \text { Profile can friend another profile to build network }\end{array}$ & 3 \\
\hline
\end{tabular}

Table 2 provides a summary of strategies and resources used by each of the seven states. The states varied in their processes for decision-making, approval, Facebook format, and their development of a social media policy. States also varied in their assessment of how valuable Facebook was to their overall outreach and youth engagement strategies.

\section{Findings and Discussion}

\section{Obtaining Consent}

In standard practice, a social work clinician will obtain consent from their client prior to providing any form of treatment or intervention. This effort not only protects the clinician and the clinician's non-profit or government agency but also clarifies expectations and boundaries for the client. The NASW Code of Ethics, 1.03 states that "social workers should provide services to clients only in the context of a professional relationship based, when appropriate, on valid informed consent” (NASW, 2008, p. 7). The code further explains what consent entails by adding that "social workers should use clear and understandable language to inform clients of the purpose of the services, risks related to the services, limits to services, etc.” (NASW, 2008, p. 8). Obtaining consent is a fundamental part of the clinician-client relationship and is an ethically essential part of the therapeutic relationship. 
Table 2: Description of Facebook Strategies, Practices, and Policies by State

\begin{tabular}{|c|c|}
\hline Case & Description \\
\hline$\overline{\text { State A }}$ & $\begin{array}{l}\text { Contracted with a university to implement NYTD } \\
\text { - Model: Open Page } \\
\text { - Approval Process: The state child welfare authority approves a biannual content plan } \\
\text { - Social Media Policy: Yes, the state and the university have a social media policy in } \\
\text { place } \\
\text { - Importance to overall outreach strategy: Not important }\end{array}$ \\
\hline State B & $\begin{array}{l}\text { Contracted with a non-profit to implement NYTD } \\
\text { - Model: Open Page } \\
\text { - Approval Process: The state child welfare authority does not review or approve } \\
\text { content } \\
\text { - Social Media Policy: The state and the non-profit do not have a social media policy } \\
\text { in place; Process documentation does exists } \\
\text { - Importance to overall outreach strategy: Important }\end{array}$ \\
\hline State C & $\begin{array}{l}\text { Contracted with voluntary agency to implement NYTD } \\
\text { - Model: Open Page; Professional Profiles } \\
\text { - Approval Process: The state child welfare authority has a low level of approval of } \\
\text { Facebook content } \\
\text { - Social Media Policy: The state and the non-profit do not have a social media policy } \\
\text { in place } \\
\text { - Importance to overall outreach strategy: Most important }\end{array}$ \\
\hline State D & $\begin{array}{l}\text { Contracted with non-profit to implement NYTD } \\
\text { - Model: Open Page; Professional Profiles } \\
\text { - Approval Process: The state child welfare authority has low level of approval of } \\
\text { Facebook content } \\
\text { - Social Media Policy: The state and the non-profit do not have a social media policy } \\
\text { in place } \\
\text { - Importance to overall outreach strategy: Most important }\end{array}$ \\
\hline State E & $\begin{array}{l}\text { Contracted with university to implement NYTD } \\
\text { - Model: Private Group } \\
\text { - Approval Process: The state child welfare authority has no required approval of } \\
\text { Facebook content } \\
\text { - Social Media Policy: The state and the non-profit do not have a social media policy } \\
\text { in place } \\
\text { - Importance to overall outreach strategy: Most important }\end{array}$ \\
\hline State F & $\begin{array}{l}\text { Contracted with university to implement NYTD } \\
\text { - Model: Open Page } \\
\text { - Approval Process: The state child welfare authority has a high level of approval of } \\
\text { Facebook content } \\
\text { - Social Media Policy: The state and the non-profit do not have a social media policy } \\
\text { in place; Process documentation does exist } \\
\text { - Importance to overall outreach strategy: Not important }\end{array}$ \\
\hline State G & $\begin{array}{l}\text { State authority implements NYTD } \\
\text { - Model: Open Page; Professional Profiles } \\
\text { - Approval Process: N/A - State implementation } \\
\text { - Social Media Policy: The State does have a social media policy } \\
\text { - Importance to overall outreach strategy: Most important }\end{array}$ \\
\hline
\end{tabular}


This component of social work practice is no less important when engaging with clients or consumers online. When referring to the use of technology, the NASW Code of Ethics, 1.03 states that "social workers who provide services via electronic media (such as computer, telephone, radio, and television) should inform recipients of the limitations and risks associated with such services” (NASW, 2008, p. 8). It can be implied that the reference to computers in this ethical standard is intended to include websites, social media, and email, even though these are not explicitly mentioned within the NASW Code of Ethics.

The ASWB Standards for Technology also mention obtaining consent in Standard 95 ; however, this standard only refers to research. The standard states "social workers conducting, evaluating, disseminating, or implementing research using technological approaches shall do so in a manner that ensures ethical credibility and ensures the informed consent of the participant” (NASW, 2005, p. 15). When applying this standard in practice, ASWB suggests that "a risk-management plan is highly recommended, and should include protocols and policies for all technologies used by the agency for all administrative, managerial, and social worker-related purposes” (NASW, 2005, p. 14). Depending on the type of organization, some government agencies implementing Facebook with youth in foster care were required to establish strict procedures and protocols for their social media strategy, whereas non-profit agencies participating in the data collection effort through a contract with a government agency were left to devise their own standards for approval and implementation.

States used a variety of methods to obtain consent from youth prior to beginning Facebook relationship. Some states included specific social media consent language within the survey content used for data collection, indicating that if youth provided their social media information (i.e., Facebook name or Twitter handle), they were agreeing to allow the representative to contact them. Other states obtained more formal documentation of social media consent by asking youth over the age of 18 to sign consent forms in person agreeing to be contacted by the representative through Facebook. To avoid concerns of obtaining parental or guardian consent for youth under the age of18, one state determined that they were not going to use social media to engage with any youth who were not old enough to provide consent for themselves.

On a very high level, some states considered a young person's-initiated act of "liking" a Facebook page or joining a private group as consent to participate. Facebook requires that all users who create a personal profile or professional page agree to their terms of use, which state "By using or accessing Facebook Services, you agree that we can collect and use such content and information in accordance with the Data Policy as amended from time to time" (Facebook, 2013, ๆ21). Some states use the Facebook terms of use as sufficient consent, arguing that if youth are over the age of 18, they are legally able to consent for themselves and are accountable for their actions on Facebook.

\section{Preserving Confidentiality Online}

Given that current and former foster care youth are members of a vulnerable population, all states interviewed heavily considered the implications that a Facebook 
relationship has on the ability to maintain confidentiality. The NASW Code of Ethics 1.07 Privacy and Confidentiality states "social workers should take precautions to ensure and maintain the confidentiality of information transmitted to other parties through the use of computers, electronic mail, facsimile machines, telephones and telephone answering machines, and other electronic or computer technology" (NASW, 2008, p. 12). Echoing the NASW Code of Ethics, standard 7 of the ASWB Standards of Technology states "social workers shall protect client privacy when using technology in their practice and document all services, taking special safeguards to protect client information in the electronic record” (NASW, 2005, p. 9).

In making confidentiality a top priority in the development of their social media strategy, some states decided to limit the ability for users to interact on their Facebook page, ensuring that information could not be shared publicly unless approved by the Facebook page administrator. Interactions were kept to private messages, and in some instances states would only interact with youth who initiated private conversations.

State representatives who created a private, opt-in Facebook group felt that youth over the age of 18 who provided confidential information online were able to consent to online interactions about that information. All state representatives interviewed took precautions to ensure that, as social media account administrators, they would not share confidential information online. Communication directed towards a specific young person through Facebook would be conducted through private messages, not public wall posts or public comments.

\section{Avoiding Disclosure of Foster Care Status or Affiliation}

NASW Code of Ethics 1.07 Privacy and Confidentiality states that "social workers should inform clients, to the extent possible, about the disclosure of confidential information and the potential consequences" (NASW, 2008, p. 10). When discussing disclosure concerns with states, all state representatives recognized the importance of allowing youth to engage with them through social media without the expense of disclosing their current foster care status or former foster care affiliation.

To avoid disclosing identities, some states selected to use an open, public, and professional Facebook page instead of a personal Facebook profile tied to a specific employee. State representatives indicated that the open Facebook page removed the assumption that anyone interacting with or "liking" the page was affiliated with the child welfare system since the page was public. A consequence of keeping a professional Facebook page was the inability to interact directly with specific youth, and states indicated that in some instances this was preventive in their social media efforts.

To address this issue, one state decided to remove all mention of foster care from the professional Facebook page and instead switched to a personal Facebook profile. By removing all mention of foster care from the profile content, assumptions could not be made about foster care status or affiliation. This state decided to revise the language to say "youth survey" instead of "foster care survey," intending to remove any undue harm in associating with their profile. For some states using private Facebook group to interact 
with foster youth, state representatives assumed that all members shared the same implied foster care affiliation, and as a result, disclosure concerns were not present.

As a result of varying contracts, agency roles, and government policies, states had different procedures and protocols for addressing disclosure concerns. Some states were required to have approval from the legal counsel within their state child welfare authority, whereas others were only accountable to their individual agency policies and liabilities.

\section{Verifying Youth Identity}

All interviewees recognized the potential dangers of contacting the wrong individual when starting an online engagement with a former or current foster youth. While the NASW Code of Ethics fails to offer guidance on online identity verification, the NASW and ASWB Standards for Technology describe the importance of verifying identity prior to engaging online. Standard 6 of the NASW and ASWB Standards for Technology states "social workers who use electronic means to provide services shall represent themselves to the public with accuracy and make efforts to verify client identity and contact information" (NASW, 2005, p. 9). Although this standard mentions the verification of identity, the NASW and ASWB interpretation of this standard only outlines the importance for clients to verify the identity and credentials of those claiming to be social workers online, not vice versa. Their interpretation indicates that "social workers need to provide their full name, credentials, licensure information, office address and phone number, and e-mail address" (NASW, 2005, p. 9). No guidance on how social workers should verify the identity of their clients prior to engaging through social media is provided.

However, states recognized the potential dangers of disclosing information and violating both consent and confidentiality when attempting to begin an online relationship with the wrong former or current foster youth. States adopted a variety of methods to confirm that the Facebook profile they were viewing was that of the intended person. Some states sent a private Facebook message, void of all mention of the survey or foster care affiliation, to the young person, and simply asked for a date of birth verification. Other states used email address and locations provided by the young person during initial data collection efforts to verify the email address and location listed on the profile.

Depending on the state's child welfare records database, some records included photos of the young person that were then compared to photos on the Facebook profile. Once the correct profile had been found, one state took these methods even further and searched through each young person's list of Facebook friends for identified family members and friends, cross-referencing the names found with the names affiliated with that individual's case records. A few smaller states confirmed identity in person, asking youth to pull up their Facebook profile once they agreed to allow the state representative to contact them online.

Each state in our study was able to interpret the standards within their own context and consider the implications when developing their Facebook strategy. However, the outcomes of their interpretation and application of the Code of Ethics and Standards for 
Technology were not always consistent, indicating that the states had varying perspectives on what the ethics and standards meant and how they should be applied in practice. Table 3 summarizes useful practices used by NYTD administrators to uphold these four ethical standards and to avoid ethical mistakes.

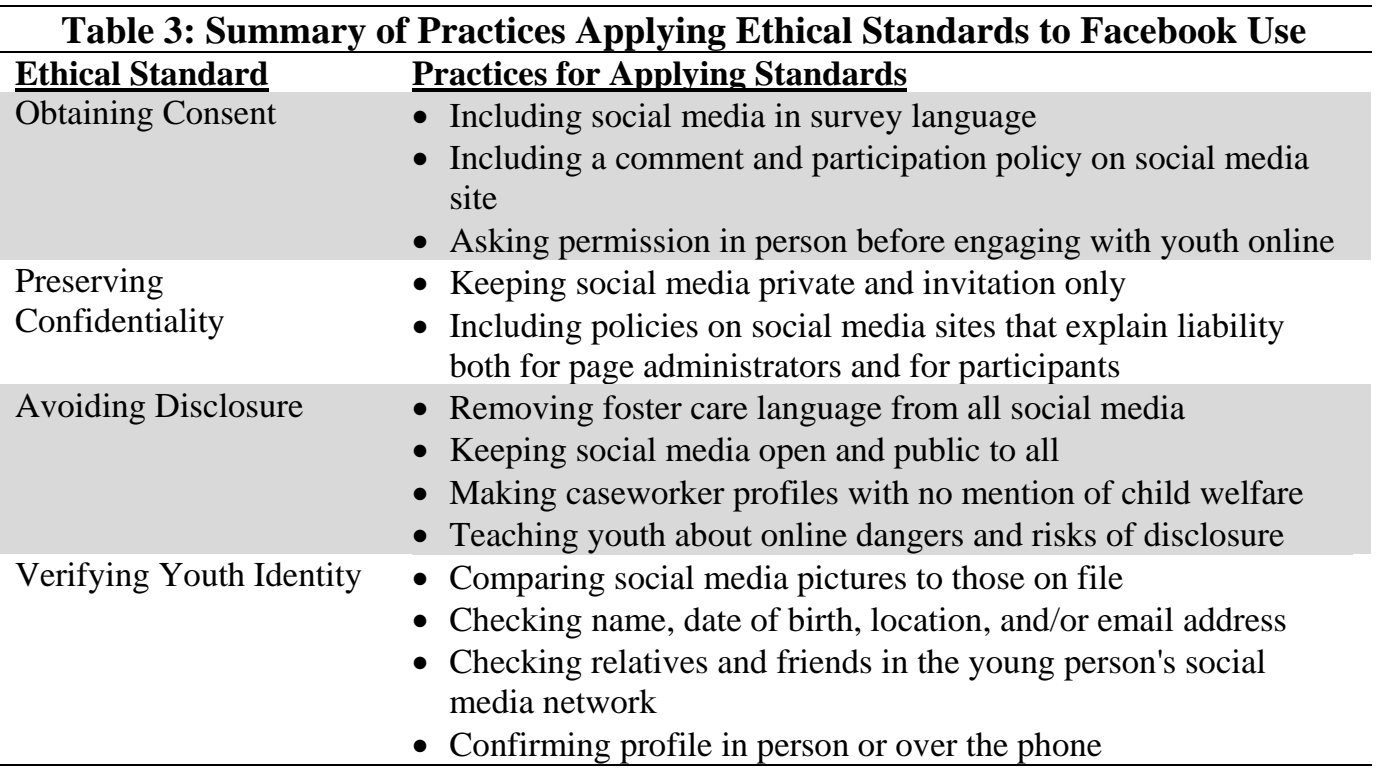

\section{Discussion and Future Research}

When compared to the NASW Code of Ethics and the and ASWB Standards for Technology, it appears that these states were able to interpret the standards within their own context and consider their implications when developing their social media strategy. However, the outcomes of their interpretation and application of the Code of Ethics and Standards for Technology were not always consistent, indicating that the states had varying perspectives on what the ethics and standards meant and how they should be applied in practice.

The NASW Code of Ethics was last updated in 2008, and the NASW and ASWB Standards for Technology has not been revised since its inception in 2005. Since 2008, the number of active monthly Facebook users has grown from 100 million users to over 1 billion. Facebook continues to be the leading SNS, closely followed by Twitter, Pinterest, and YouTube. These tools have become a staple in human interaction and are being applied in a variety of personal and professional settings, including non-profits and government agencies.

The NASW and ASWB Standards for Technology define technology as "a set of prescribed events that are embedded in hardware, software, or telecommunications and that direct activities, decisions, or choices” (NASW, 2005, p. 20). However, neither the NASW Code of Ethics nor the NASW and ASWB Standards for Technology define, mention, or address the ethical considerations for social media use. There are several 
examples of how non-profits and government agencies are currently applying SNS and social media tools based on their individual interpretation of these ethical standards.

Reamer (2013) highlights three sets of ethical risks relevant to using social media tools, particularly in social work practice: ethical mistakes, ethical decisions, and ethical misconduct. An ethical mistake, such as not obtaining a client's full informed consent, can occur by omission or by commission (Reamer, 2013). Ethical mistakes are different from ethical decisions and misconduct (Reamer, 2013). Future research and standard development could include Reamer's ethical framework when evaluating ethical social media use within social work practice.

A 2009 NASW News issue included an article titled "New Technology Transforming Profession," where the ASWB Director of Board Services is quoted saying "there are some states that have taken a hard look at this issue and are making some changes. However, there is still confusion about how to regulate and what to regulate" (as cited in Sfiligoj, 2009, p. 1). With little to no ethical guidance on social media use in the context of social work practice, social workers will continue to adopt SNS and social media based on their own interpretation of the standards. Although the state representatives interviewed in this study were able to adequately interpret and apply those standards, enforcement of ethical violations will be difficult without explicit guidelines, protocols, and procedures for social media use.

Social media continues to revolutionize the way social workers provide services, connect with clients, and engage with broader society. Further research is needed into the evaluation of social media best practices within the social work profession. Further ethical and legal guidance is needed to ensure that social workers are utilizing new and developing technologies appropriately and with key social work values and principles in mind.

\section{References}

American Youth Policy Forum. (2014). At-risk youth (Foster youth/juvenile justice). Retrieved September 29, 2014, from http://www.aypf.org/programareas/at-riskyouth-foster-youthjuvenile-justice/

Balfe, M., Hackett, S., Masson, H., \& Phillips, J. (2013). Lost without a trace? Social networking and social research with a hard-to-reach population. British Journal of Social Work, 43, 24-40. doi:10.1093/bjsw/bcr168

Congress, E., \& McAuliffe, D. (2006). Social work ethics: Professional codes in Australia and the United States. International Social Work, 49(2), 151-164. doi:10.1177/0020872806061211

Facebook. (2013). Facebook statement of rights and responsibilities. Retrieved July 18, 2013, from https://www.facebook.com/legal/terms

Hrdinova, J., Helbig, N., \& Stollar-Peters, C. (2010). Designing social media policy for government: Eight essential elements. Retrieved September 30, 2014, from 
http://ctg.albany.edu/publications/guides/social_media_policy/social_media_policy.p $\mathrm{df}$

National Association of Social Workers [NASW]. (2005). NASW \& ASWB standards for technology and social work practice. Retrieved July, 18, 2013, from http://www.aswb.org/pdfs/TechnologySWPractice.pdf

NASW. (2008). Code of ethics of the National Association of Social Workers. Retrieved July 18, 2013, from http://www.socialworkers.org/pubs/code/default.asp

National Association of State Chief Information Officers [NASCIO]. (2010). A national survey of social media in state government: Friends, followers, and feeds. Retrieved September 30, 2014, from http://www.nascio.org/publications/documents/nasciosocialmedia.pdf

Oxley, A. (2011). Strengthening cybersecurity series: A best practices guide for mitigating risk in the use of social media. Retrieved September 30, 2014, from http://www.businessofgovernment.org/report/best-practices-guide-mitigating-riskuse-social-media

Perron, B. E., Taylor, H. O., Glass, J. E., \& Margerum-Leys, J. (2010). Information and communication technologies in social work. Advances in Social Work, 11(2), 67-81.

Reamer, F. G. (2013). Social work in a digital age: Ethical and risk management challenges. Social Work, 58(2), 163-172. doi:10.1093/sw/swt003

Sewpaul,V., \& Jones, D. (2004). Global standards for social work education and training. Social Work Education, 23(5), 493-513. doi:10.1080/0261547042000252244

Sfiligoj, H. (2009). NASW News: New technology transforming profession. Retrieved July 16, 2013, from http://www.naswdc.org/pubs/news/2009/09/default.asp

\section{Author note}

Address correspondence to: Hillary R. Dolinsky, LMSW, Center for Technology in Government, University at Albany, State University of New York, 187 Wolf Road, Suite 301, Albany NY 12205. Email: hdolinsky@ctg.albany.edu 